\title{
Health-Related Quality of Life of Asylum Seekers and Refugees in Germany: a Cross-Sectional Study with Data from the German Socio-Economic Panel
}

\author{
Thomas Grochtdreis $^{1}$ (D) - Hans-Helmut König ${ }^{1}$ • Steffi G. Riedel-Heller ${ }^{2}$ • \\ Judith Dams ${ }^{1}$
}

Received: 2 March 2020 / Accepted: 19 October 2020 / Published online: 1 November 2020

(C) The Author(s) 2020

\begin{abstract}
The purpose of this study was to estimate the health-related quality of life (HrQoL) of asylum seekers and refugees that arrived during the European migrant and refugee crisis in Germany between 2014 and 2017. The analysis was based on the 2016 and 2017 refugee samples of the German Socio-Economic Panel $(n=6821)$. HrQoL was measured using a modified version of the SF-12v2 questionnaire and presented as physical (PCS) and mental (MCS) component summary scores. PCS and MCS scores for the total sample, males and females were calculated by sociodemographic characteristics. Associations between PCS and MCS scores and sociodemographic variables were examined by a linear regression with bootstrapped standard errors. The mean PCS and MCS scores of the sample were 53.4 and 47.9, respectively. Female sex was statistically significantly associated with lower PCS and MCS scores. The SF-12 subscale general health was valued highest with a score of 55.4, whereas the subscale role emotional was valued lowest with a score of 46.9. Employment was statistically significantly associated with higher PCS and MCS scores. Persons from Afghanistan had statistically significantly lower MCS scores than persons from Syria, whereas MCS scores were statistically significantly higher for persons from Eritrea. Physical and mental HrQoL of asylum seekers and refugees that arrived during the European migrant and refugee crisis in Germany between 2014 and 2017 was higher and lower than the German norm, respectively. Female sex, older age, unemployment and being separated, divorced or widowed were negatively
\end{abstract}

Supplementary Information The online version contains supplementary material available at https://doi.org/ 10.1007/s11482-020-09877-4.

Thomas Grochtdreis

t.grochtdreis@uke.de

1 Department of Health Economics and Health Services Research, Hamburg Center for Health Economics, University Medical Center Hamburg-Eppendorf, Hamburg, Germany

2 Institute of Social Medicine, Occupational Health and Public Health (ISAP), Medical Faculty, University of Leipzig, Leipzig, Germany 
associated with HrQoL. The three largest ethnical groups of asylum seekers and refugees, Syrians, Afghans and Eritreans, differ inherently in their HrQoL.

Keywords SF-12 $\cdot$ Surveys and questionnaires $\cdot$ Health $\cdot$ Quality of life $\cdot$ Refugees

\section{Introduction}

From 2014 to 2017, the member states of the European Union (EU) were experiencing an increased number of asylum applications. In 2014, the number of asylum and first time asylum seekers in the EU was 626,960. In the following two years, the number of applicants increased to $1,322,845$ and 1,260,910. After 2016, the number of applicants decreased again to 712,235 (Eurostat 2019). Germany, together with Sweden, has played a key role during the so-called European migrant and refugee crisis (UNHCR 2016). This key role is emphasized by the percentage of persons who applied for international protection in Germany, which increased from already high $31 \%$ of all applicants in the EU in the year 2014 to even 59\% in the year 2016 (Eurostat 2019).

Before and during their flight, asylum seekers are confronted with harsh conditions implying physical and psychological stress (Jesuthasan et al. 2018). The health consequences of the flight include nutritional deficiencies, bodily injuries, infections, respiratory diseases, dental diseases, skin diseases, gastrointestinal disorders and mental disorders (Jesuthasan et al. 2018, Bischoff et al. 2009, Goodman et al. 2018, Laukamp et al. 2019, Marquardt et al. 2016, van Berlaer et al. 2016, Richter et al. 2018, Theuring et al. 2016, Bauhoff and Gopffarth 2018). Within the first three months after arrival, asylum seekers are often diagnosed with infections and respiratory diseases due to poor hygienic conditions and bad housing conditions (Goodman et al. 2018, Laukamp et al. 2019). Furthermore, after their arrival in the receiving country in Europe, asylum seekers and refugees have a high burden of disease and are at high risk of mental health disorders, predominantly trauma, stress-related disorders, schizophrenia, schizotypal and delusional disorders, and affective disorders (Richter et al. 2018, Bauhoff and Gopffarth 2018, Winkler et al. 2019, Biddle et al. 2019, Nesterko et al. 2019, Nesterko et al. 2020a, Nesterko et al. 2020b).

A theoretical model of the International Organization for Migration (IOM) showed a complex relationship between migration and health (International Organization for Migration 2020). Health of migrants is influenced by social determinants, such as socio-economic, individual and legal factors. Especially asylum seekers and refugees are at risk of health-related vulnerabilities due to unmet needs in health services utilization, poor hygienic and bad housing conditions. A German cohort study analyzed the healthcare utilization behavior of asylum seekers that arrived during the European migrant and refugee crisis. It was emphasized that during the stay at the reception center nearly half of the refugees had utilized primary healthcare with a mean of 3.1 visits per patient during on average 41 days of camp inhabitation (Wetzke et al. 2018). Furthermore, an analysis of claims data reported that asylum seekers utilized inpatient care and emergency department care twice as often compared with regularly insured persons (Bauhoff and Gopffarth 2018). However, it remains unclear, whether such issues in health care provision and also the unmet needs in health services utilization (Biddle et al. 2019) have an influence on health and (health-related) quality of life. 
To date, only few studies have investigated (health-related) quality of life of asylum seekers and refugees that arrived in Germany during the European migrant and refugee crisis. Five studies described health and quality of life among asylum seekers and refugees in Sweden, Italy and Germany (Jesuthasan et al. 2018, Gottvall et al. 2019, Leiler et al. 2019, Nante et al. 2016, Adedeji and Bullinger 2019). Quality of life of female refugees that arrived in Germany was lower in all domains of the EUROHISQOL questionnaire compared with persons from the EU region and was associated with age and education (Jesuthasan et al. 2018, Schmidt et al. 2006). In another study, quality of life of asylum seekers and refugees from Sub-Saharan African that were staying in Germany was also lower in all domains of the WHOQOL-BREF measure (Adedeji and Bullinger 2019).

Concerning health and quality of life of asylum seekers and refugees that arrived in Germany, Liebau (2016) has annotated the analysis potential of data of the German Socio-Economic Panel (SOEP). The SOEP is a large, nationally representative, annual, population based study in Germany with specific migration and refugee samples that routinely measures $\mathrm{HrQoL}$ and is therefore of great importance for quality of life research (Goebel et al. 2019). Earlier studies based on data of the SOEP focused on the healthy-migrant-effect, the health of migrant workers as well as health and quality of life in general (e.g. Angelini et al. (2012), Igel et al. (2010), Nesterko et al. (2013), Razum and Rohrmann (2002)). However, HrQoL of asylum seekers and refugees that recently arrived in Germany has not yet been reported, just as whether particular sociodemographic characteristics, such as the nationality, are associated with HrQoL. It is hypothesized that the HrQoL of asylum seekers and refugees that recently arrived in Germany might be low, as a result of a high burden of disease and a high risk of mental health disorders accompanied by unmet needs of health care. Furthermore, the extent of the influence between social determinants and the HrQoL of asylum seekers and refugees is not known. Therefore, the aim of this study was to estimate the HrQoL of asylum seekers and refugees that arrived during the European migrant and refugee crisis in Germany between 2014 and 2017 based on the SOEP.

\section{Material and Methods}

\section{Sample}

The sample of this study was based on cross-sectional data of the SOEP, located at the German Institute for Economic Research (DIW Berlin). The SOEP is a representative German household panel that interviewed over 20,000 participants annually since 1984. In order to ensure that the recent immigration of asylum seekers and refugees from the Middle East, in particular Syria, to Germany is represented in the SOEP, additional refugee samples were integrated into the SOEP in 2016 and 2017 (Goebel et al. 2019). The refugee samples were drawn from the German Central Register of Foreigners and sampled using a two-stage clustered disproportional stratified sampling design (Kühne et al. 2019, Kroh et al. 2017). The primary sampling units were regional clusters of immigration offices stratified by federal states and differentiated by county type. Within these sampling units, persons were selected based on a disproportional sampling scheme and were added to the sample, including each 
household member 17 years or older (Kühne et al. 2019). Interview materials were provided in the languages German, English, Arabic, Farsi, Pashto, Urdu and Kurjmanji (Kühne et al. 2019).

Out of those refugee samples, persons with proof of arrival in Germany issued between 2014 and 2017 were included to the study sample in order to cover those asylum seekers and refugees that arrived during the European migrant and refugee crisis $(68.2 \%, n=6858)$. The net sample was further restricted to only first-time participants of the SOEP $(67.8 \%, n=6821)$. The net sample was not further restricted according to sociodemographic characteristics. Refugees were defined according to the UNHCR as "people who cannot return to their country of origin because of a wellfounded fear of persecution, conflict, violence, or other circumstances that have seriously disturbed public order, and who, as a result, require international protection" (UNHCR 2020). On the basis of the outcome of the asylum application, asylum seekers and refugees were categorized as entitled to protection (recognized refugee, recognized asylum seeker, recognized other protection status), with temporary suspension of deportation, with request to leave the country, and with pending decision of asylum application. All persons from the net sample had a direct migration background (i.e. both parents were not born in Germany).

\section{Measures}

A modified version of the SF-12v2 questionnaire was used to measure HrQoL in the SOEP (Andersen et al. 2007, Schupp et al. 2007). The SF-12 is a standardized questionnaire consisting of 12 items within the eight subscales: physical functioning, physical role limitations, bodily pain, general health, vitality, social functioning, emotional role limitations and mental health (Ware et al. 1996). The SF-12 questionnaire in the SOEP contains one additional question from the SF-36 about 'severe physical pain', whereas the question about 'work interference due to pain' is missing. Furthermore, the SF-12 questionnaire in the SOEP deviates to some extent in the layout, and the form and order of questions (Schupp et al. 2007). However, in order to do justice to those differences to the original version, instead of the US normative sample, a German normative sample based on SOEP data has been used for computation of the SF-12 summary scores (Schupp et al. 2007).

The SF-12 subscales were Z-transformed by norm-based scoring using the average values and standard deviations of the German normative sample (Andersen et al. 2007, Nübling et al. 2006). The items of the dimensions physical functioning, role limitations, social functioning and pain were combined to a physical component summary (PCS) score, and the dimensions social functioning, emotional role limitations and mental health were combined to a mental component summary (MCS) score, respectively. Thus, physical and mental HrQoL is represented by the SF-12 subscales as well as the PCS and the MCS score. Because of the Z-transformation, all scales ranged from 0 to 100 (with higher scores representing better health).

The self-reported sociodemographic variables sex, age, marital status (never married/single, married/in partnership, separated/divorced and widowed), employment status (employed, unemployed and apprenticeship), nationality and religious affiliation were used to describe the sample. Age of persons was categorized into the groups of $18-24,25-34,35-44$ and $\geq 45$ years. Nationality was categorized into Syria, 
Afghanistan, Iraq, Eritrea, other African countries (without Eritrea), other Asian countries (without Syria, Afghanistan and Iraq), European countries and ethnic minorities/ stateless persons. Religious affiliation was categorized into Muslim, Christian, other faith and non-denominational. Furthermore, years since proof of arrival in Germany (survey year minus year of proof of arrival in Germany) and outcome of asylum application (entitlement to protection, suspension of deportation, request to leave the country, decision pending) were used to describe the sample.

\section{Statistical Analysis}

As the rate of missing information was low (1.42\%), missing values were not imputed. Observations with missing information were removed from the analyses by listwise deletion.

Descriptive statistics of sociodemographic variables were calculated for the total sample. PCS and MCS scores for the total sample were calculated by sociodemographic characteristics. PCS and MCS were not normally distributed and comparison groups were assumed to be unrelated. Therefore, differences in PCS and MCS scores by sociodemographic characteristics were tested using Wilcoxon rank-sum test and Kruskal-Wallis equality-of-populations rank test.

Associations between PCS and MCS scores and sociodemographic variables were examined using linear regressions with bootstrapped confidence intervals. According to the Shapiro-Francia $\mathrm{W}^{\prime}$ test for normality and the Breusch-Pagan test for heteroskedasticity, both, residuals of the regressions of PCS and MCS, were not normally distributed and variances of the dependent variables were not homogenous, respectively. Linearity of PCS and MCS and dependent variables was assumed and no multicollinearity of dependent variables was detected using the variance inflation factor. Two models with PCS and MCS scores as dependent variables examined the associations with the independent variables sex, age, employment, marital status, nationality, years since proof of arrival in Germany and outcome of asylum application.

All analyses were performed using Stata/SE 15.1 (StataCorp, TX, USA). All applied statistics were two-sided. In total, 51 tests for statistical significance of group differences in sociodemographic characteristics and mean PCS/MCS scores were conducted. Therefore, the level of significance was set at $\alpha=0.001(0.05 / 51)$ to correct for multiple significance tests to avoid a type I error (Dickhaus 2014).

\section{Results}

The characteristics of the sample $(n=6821)$ are shown in Table 1 . The majority of the sample was male $(61.1 \% ; n=4168)$ and the mean age was 32.9 years, with females being older than males (33.6 vs 32.5 years; $p<0.001$; data not shown). Of the total sample, $54.9 \%(n=3619)$ were married or in a partnership, $32.0 \%(n=2111)$ have never been married or were single, and $11.2 \%(n=735)$ were separated or divorced. Almost all persons of the sample were unemployed $(89.9 \% ; n=6134)$. The majority of the sample was Syrian $(50.0 \% ; n=3407)$ and indicated to belong to the Muslim religion $(72.9 \% ; n=4881)$. Furthermore, the majority of the persons of the sample 
Table 1 Characteristics of the sample

\begin{tabular}{|c|c|}
\hline Variable & Total sample $(n=6821)$ \\
\hline \multicolumn{2}{|l|}{ Sex } \\
\hline Female: $n(\%)$ & $2653(38.89)$ \\
\hline Male: $n(\%)$ & $4168(61.11)$ \\
\hline Age: mean (SD) & $32.92(10.78)$ \\
\hline 18-24: $n(\%)$ & $1744(25.57)$ \\
\hline $25-34: n(\%)$ & $2407(35.29)$ \\
\hline $35-44: n(\%)$ & $1656(24.28)$ \\
\hline$\geq 45: n(\%)$ & $1014(14.87)$ \\
\hline \multicolumn{2}{|l|}{ Marital status } \\
\hline Never married/single: $n(\%)$ & $2111(32.04)$ \\
\hline Married/in partnership: $n(\%)$ & $3619(54.92)$ \\
\hline Separated/divorced: $n(\%)$ & $735(11.15)$ \\
\hline Widowed: $n(\%)$ & $124(1.88)$ \\
\hline \multicolumn{2}{|l|}{ Employment } \\
\hline Employed: $n(\%)$ & $490(7.18)$ \\
\hline Unemployed: $n(\%)$ & $6134(89.93)$ \\
\hline Apprenticeship: $n(\%)$ & $197(2.89)$ \\
\hline \multicolumn{2}{|l|}{ Nationality } \\
\hline Syria: $n(\%)$ & 3407 (49.95) \\
\hline Afghanistan: $n(\%)$ & $915(13.41)$ \\
\hline Iraq: $n(\%)$ & $920(13.49)$ \\
\hline Eritrea: $n(\%)$ & $322(4.72)$ \\
\hline Other Africa : $n(\%)$ & $340(4.98)$ \\
\hline Other Asia ${ }^{2}: n(\%)$ & $440(6.45)$ \\
\hline Europe: $n(\%)$ & $391(5.73)$ \\
\hline Ethnic minority/stateless: $n(\%)$ & $86(1.26)$ \\
\hline \multicolumn{2}{|l|}{ Religious affiliation } \\
\hline Muslim: $n(\%)$ & $4881(72.93)$ \\
\hline Christian: $n(\%)$ & $902(13.48)$ \\
\hline Other faith: $n(\%)$ & $523(7.81)$ \\
\hline Non-denominational: $n(\%)$ & $387(5.78)$ \\
\hline \multicolumn{2}{|l|}{ Years since proof of arrival in Germany } \\
\hline $0: n(\%)$ & $406(5.95)$ \\
\hline $1: n(\%)$ & 3347 (49.07) \\
\hline $2: n(\%)$ & $2486(36.45)$ \\
\hline $3: n(\%)$ & $539(7.90)$ \\
\hline $4: n(\%)$ & $43(0.63)$ \\
\hline \multicolumn{2}{|l|}{ Outcome of asylum application } \\
\hline Entitlement to protection ${ }^{3}: n(\%)$ & $4308(64.54)$ \\
\hline Suspension of deportation: $n(\%)$ & $386(5.78)$ \\
\hline Request to leave the country: $n(\%)$ & $250(3.75)$ \\
\hline Decision pending: $n(\%)$ & $1731(25.93)$ \\
\hline
\end{tabular}

$S D$, Standard deviation

1 Without Eritrea

2 Without Syria, Afghanistan and Iraq

3 Recognized refugee, recognized asylum seeker, recognized other protection status 
arrived in Germany one to two years before the first panel survey participation $(85.5 \%$; $n=5833)$ and was entitled to protection in Germany $(64.5 \% ; n=4308)$.

The mean PCS and MCS scores in the total sample were 53.4 and 47.9, respectively. Both, the mean PCS (51.0 vs. 55.0; $p<0.001)$ and MCS (46.1 vs. $49.1 ; p<0.001)$ scores were statistically significantly lower in females than in men (Figs. 1 and 2). In addition, the mean PCS and MCS scores differed statistically significantly between different age categories $(p<0.001)$. Younger persons aged 18 to 24 years had the highest mean PCS and MCS scores (57.5 and 48.8), whereas persons aged 45 years and older had the lowest mean PCS and MCS scores (46.0 and 46.5). Both, the PCS and MCS scores differed statistically significantly by marital status, employment status and nationality (all with $p<0.001$ ). Persons that have never been married or were single had the highest mean PCS and MCS scores (57.3 and 48.7), whereas widowed persons had the lowest mean PCS and MCS scores (43.5 and 43.7). Persons that were employed had higher mean PCS and MCS scores than unemployed persons (56.0 and 50.8 vs. 53.1 and 47.6). Furthermore, mean MCS scores differed statistically significantly by

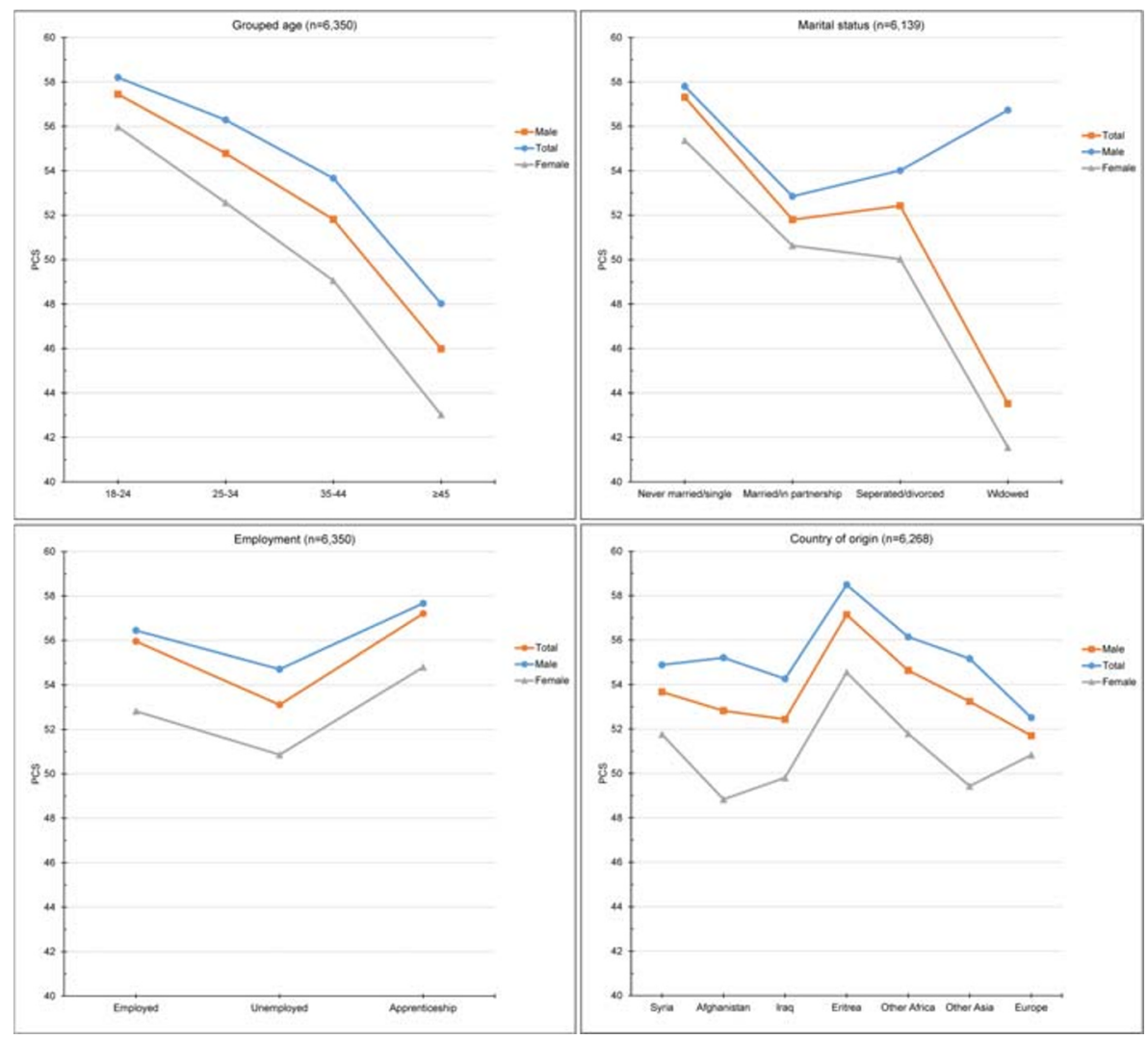

Fig. 1 Mean PCS scores by age groups, marital status, employment and country of origin by sex (all comparisons with $p \leq 0.001)$. PCS: Physical Component Summary; comparisons of mean PCS scores by categorical characteristics were analyzed using Kruskal-Wallis equality-of-populations rank test. Country of origin: without ethnic minorities/stateless persons. Other Africa: without Eritrea. Other Asia: without Syria, Afghanistan and Iraq 


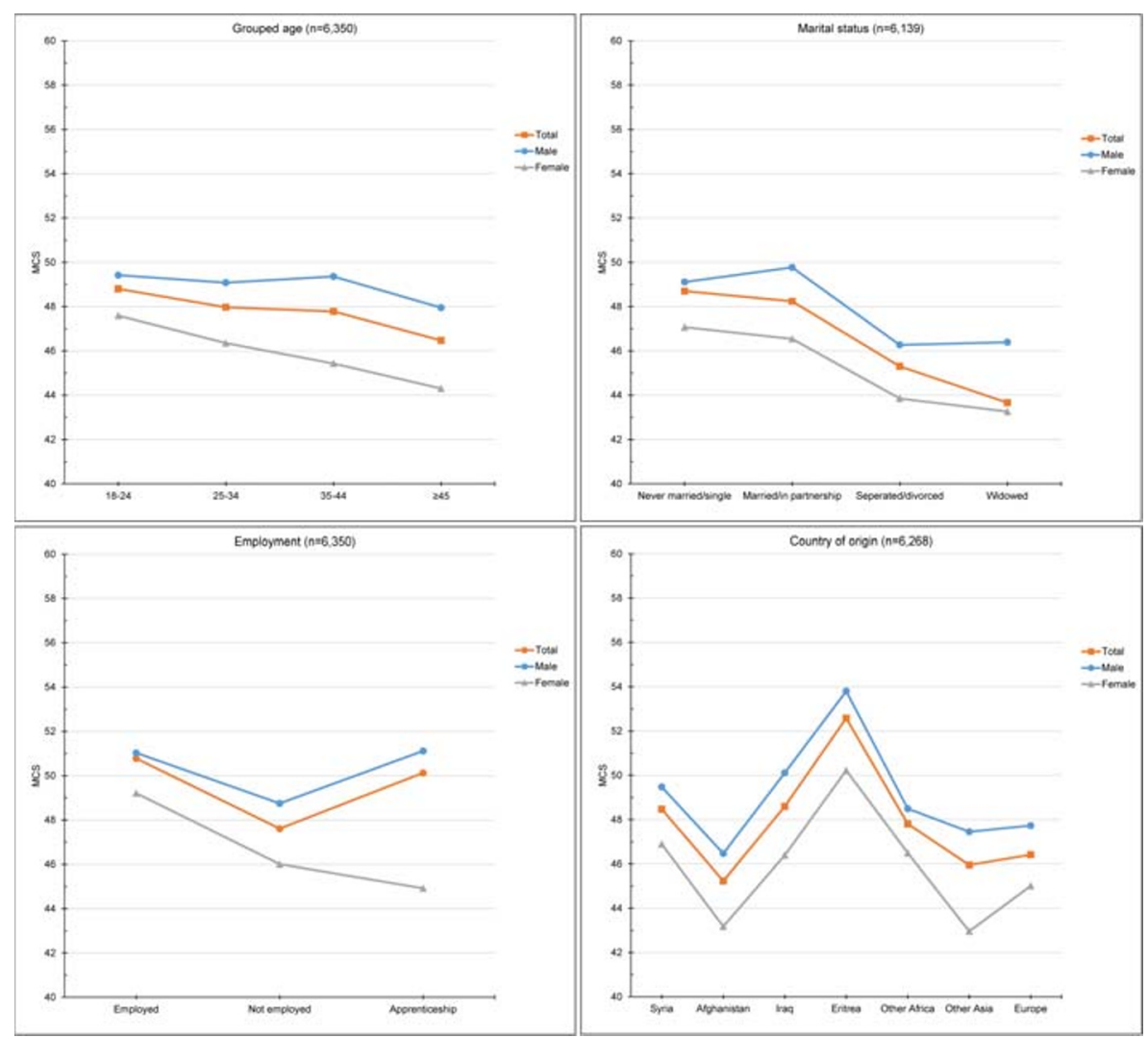

Fig. 2 Mean MCS scores by age groups, marital status, employment and country of origin by sex (all comparisons with $p \leq 0.001)$. MCS: Mental Component Summary; comparisons of mean MCS scores by categorical characteristics were analyzed using Kruskal-Wallis equality-of-populations rank test. Country of origin: without ethnic minorities/stateless persons. Other Africa: without Eritrea. Other Asia: without Syria, Afghanistan and Iraq

outcome of asylum application $(p<0.001)$. The mean PCS and MCS scores by sociodemographic characteristics are reported in the Online Resource 1.

The mean scores of the SF-12 subscales varied from 46.9 in the role emotional scale to 55.4 in the general health scale (Fig. 3). Over all SF-12 subscales, mean scores of males were statistically significantly higher than mean scores of females (all with $p<0.001$ ). All mean scores of the SF-12 subscales differed statistically significantly between different age categories (all with $p<0.001$ ). Younger persons aged 18 to 24 years had the highest mean scores over all SF-12 subscales, varying from 48.8 in the role emotional scale to 59.5 in the general health scale. Persons aged 45 years and older had the lowest mean scores, varying from 42.8 in the bodily pain scale to 50.0 in the vitality scale. All mean scores of the SF-12 subscales differed statistically significantly by marital status, employment status and nationality (all with $p<0.001$ ). Furthermore, the scales general health, vitality, social functioning, role emotional and mental health differed statistically significantly between persons with different outcomes of asylum application (all with $p<0.001$ ). The mean scores of the SF-12 subscales by sociodemographic characteristics are reported in the Online Resource 2. 


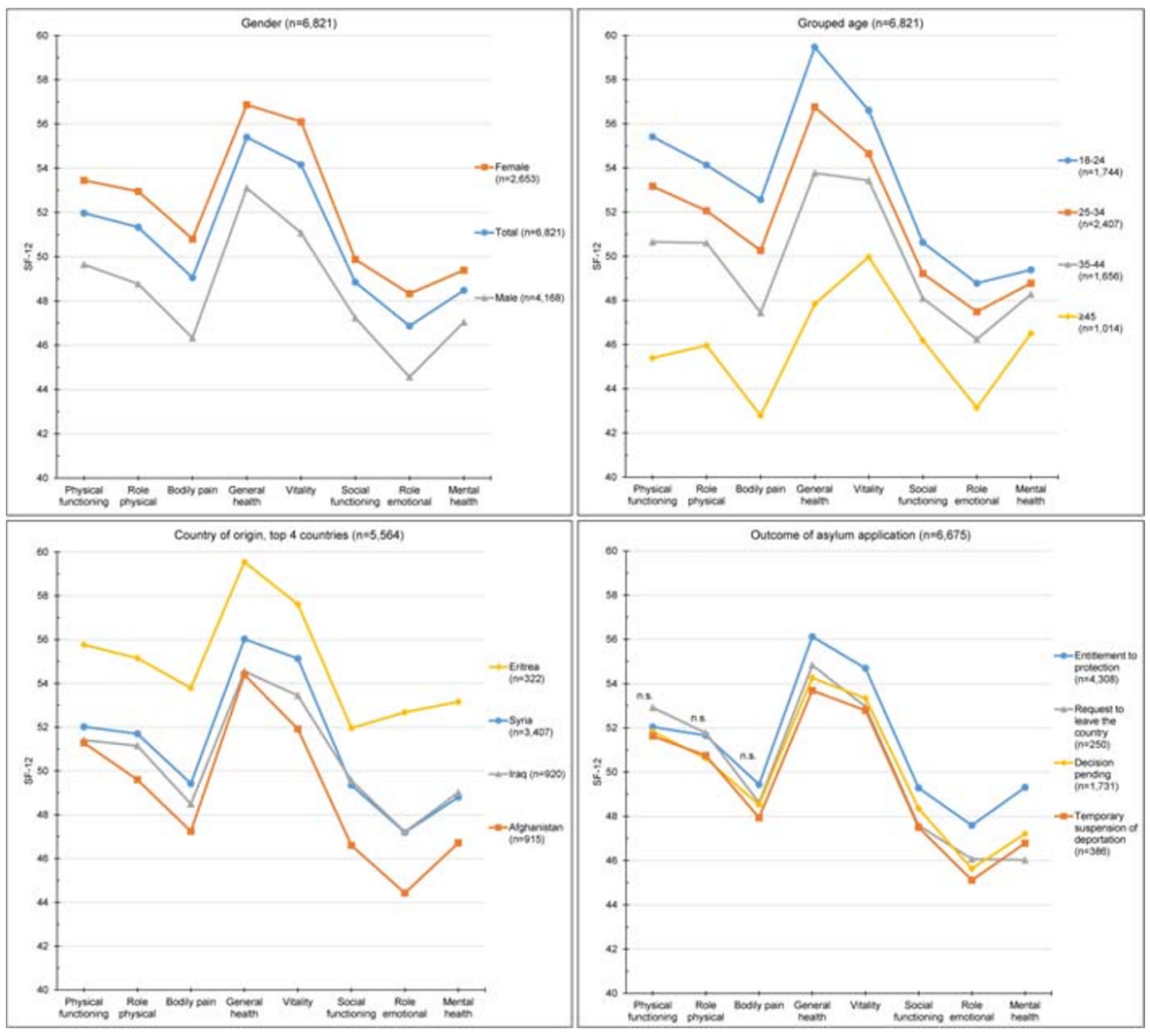

Fig. 3 Mean SF-12 subscale scores by sex, age groups, country of origin and outcome of asylum application (all significant comparisons with $p \leq 0.001$ ). n.s.: not significant, $p>0.001$

In the model with PCS as dependent variable, female sex was statistically significantly associated with a lower PCS score $(-3.2, p<0.001$; Table 2$)$. Compared with being aged 18 to 24 years, older age was statistically significantly associated with lower PCS scores $(-1.8$ to -10.1 , all with $p<0.001)$. Unemployed persons had statistically significantly lower PCS scores than employed persons $(-1.6, p<0.001)$. Furthermore, persons that were never married or single had a statistically significantly higher PCS score than persons being married or living in partnership $(+1.3, p<0.001)$. In the model with MCS as dependent variable, female sex was statistically significantly associated with a lower MCS score $(-2.9, p<0.001)$. Compared with being aged 18 to 24 years, being aged 45 and older was statistically significantly associated with a lower MCS score $(-2.3, p<0.001)$. Unemployed persons had statistically significantly lower MCS scores than employed persons $(-2.9, p<0.001)$. Persons being never married or single and separated or divorced had statistically significantly lower MCS scores than persons being married or living in partnership $(-1.5, p=0.001$ and $-3.6, p<0.001)$, respectively. Furthermore, MCS scores were statistically significantly lower for persons from Afghanistan $(-2.5, p<0.001)$ and higher for persons from Eritrea $(3.6 ; p<0.001)$ compared with persons from Syria. A temporary suspension from deportation and a 


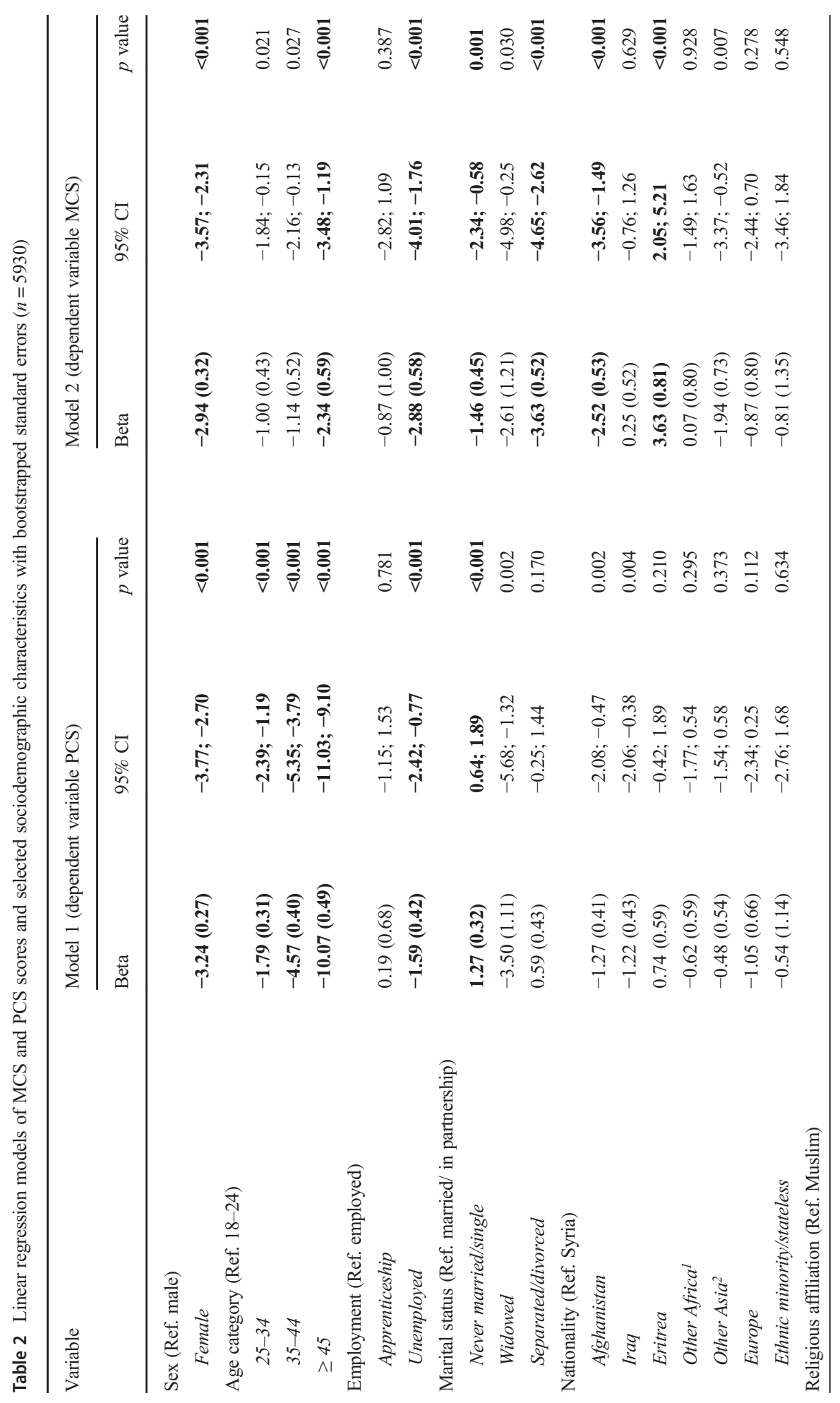




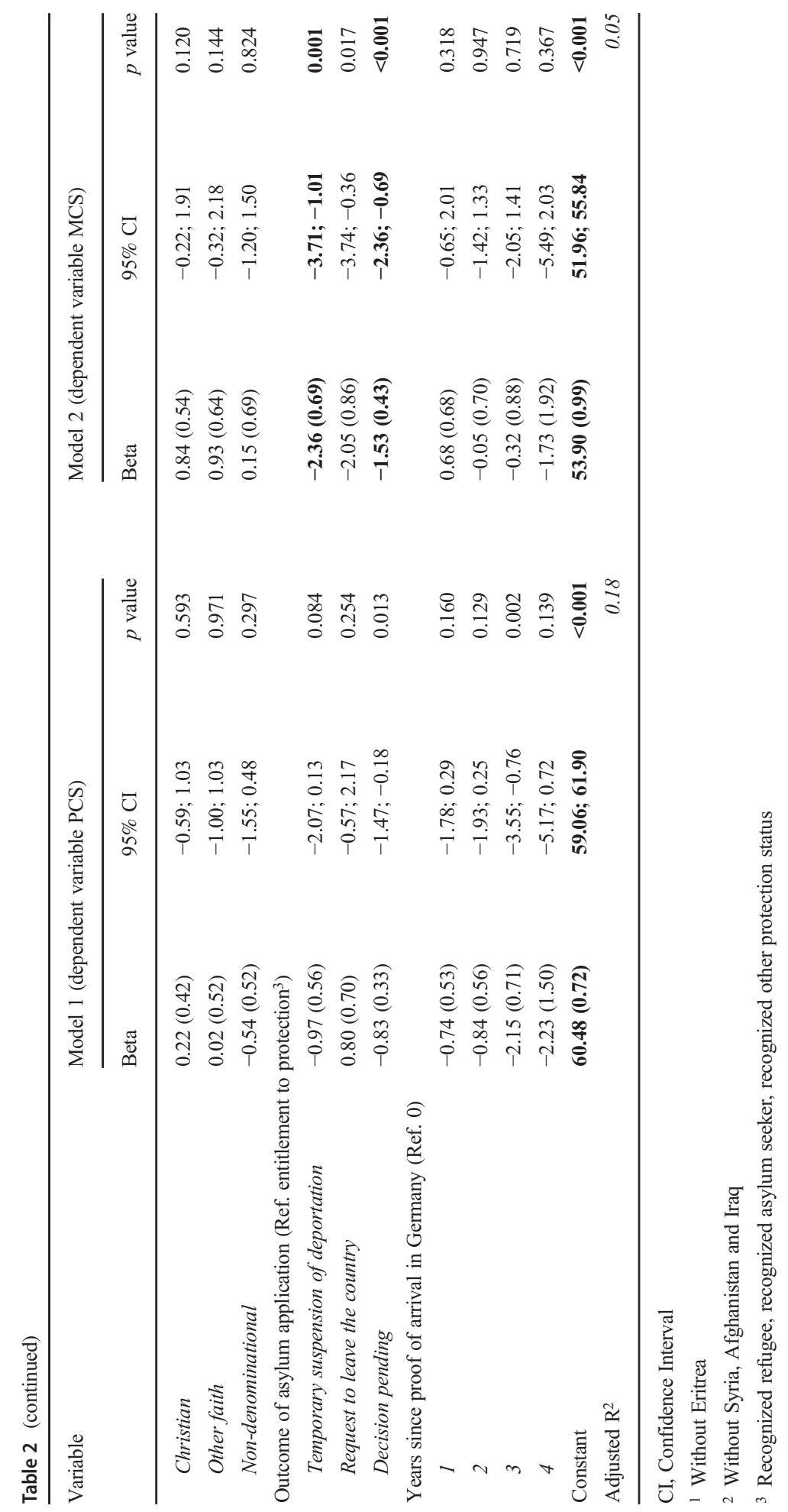


pending decision of asylum application were statistically significantly associated with lower MCS scores compared with an entitlement to protection as outcome of asylum application $(-2.4, p=0.001$ and $-1.5, p<0.001)$.

\section{Discussion}

The aim of this study was to estimate the HrQoL of asylum seekers and refugees that arrived during the European migrant and refugee crisis in Germany between 2014 and 2017. Overall, physical HrQoL of the asylum seekers and refugees was higher than of the German normative sample used for computation of the SF-12 summary scores (53.4 vs. 50.0) (Schupp et al. 2007). However, this difference may be explained by the younger age of the current sample (33 vs. 48 years). Mental HrQoL of the asylum seekers and refugees was lower (47.9 vs. 50.0). A reduced HrQoL was associated with female sex, older age, unemployment, and having never been married, being single, separated or divorced. Compared with the HrQoL of Syrian asylum seekers and refugees, the HrQoL of asylum seekers and refugees from Afghanistan was lower, whereas the HrQoL of asylum seekers and refugees from Eritrea was higher. To our knowledge, no study has been published that estimated HrQoL of Syrians, Afghans, Iraqis or Eritreans based on a representative sample. Nevertheless, the results of the current study were in correspondence with those of a systematic review that reported varying risks of poor self-perceived health across migrants and ethnic minority groups (Nielsen and Krasnik 2010). Furthermore, it was reported that a reduced HrQoL was associated with older age in a sample of asylum seekers and refugees in Italy, yet no association between HrQoL and sex was found (Nante et al. 2016). To our knowledge, the association between being separated or divorced and a reduced mental HrQoL of asylum seekers and refugees, has not been found before in any study. However, it is of note that the IOM determined the unification of the family and partner as factor positively influencing health of migrants at the arrival and integration phase, and therefore being in a partnership might have a protective effect (International Organization for Migration 2020).

The associations of female sex, older age and reduced HrQoL found in the current study have also been found by studies with representative samples of the German total population regarding associations of $\mathrm{HrQoL}$ and sociodemographic characteristics (Ellert and Kurth 2013, Grochtdreis et al. 2019). Sex and age were described already as social determinants of health of migrants by the IOM in a theoretical model (International Organization for Migration 2020). For asylum seekers and refugees that arrived in Germany, sex and age may be confirmed as social determinants of HrQoL. It remains open, whether other socioeconomic, cultural and environmental factors as well as individual factors, such as lifestyle and behavioral factors modify those associations between sex, age and HrQoL. Furthermore, in the current study, it was not possible to analyze associations between other factors that might influence HrQoL of asylum seekers and refugees, such as social exclusion, cultural values and separation from loved ones (International Organization for Migration 2020).

According to the Global Burden of Disease Study 2017, healthy life expectancy of populations from Syria, Afghanistan, and Eritrea was reduced compared with the German population (53 to 60 vs. 70 years), whereas healthy life expectancy of the 
Iraqi population was relatively high (64 years) (Global Burden of Disease DALYs and HALE Collaborators 2018). Furthermore, the mortality ratio of populations from Syria, Afghanistan, and Eritrea was increased compared with the German population (1833 to 1282 vs. 632 per 100,000 population), whereas again, the mortality ratio of the Iraqi population was only slightly different (659 per 100,000 population) (Global Burden of Disease 2017 Mortality Collaborators 2018). In Afghanistan and Eritrea, the leading cause of age-standardized years lived with disabilities was conflict and terrorism in 2017 (Global Burden of Disease 2017 Disease and Injury Incidence and Prevalence Collaborators 2018). On the Human Development Index, a summary measure of achievements in living a long and healthy life, having access to knowledge and a decent standard of living, the countries Syria, Afghanistan, and Eritrea ranked in the rear third (ranks 154 to 182), whereas the rank of Iraq was 120 of all 189 countries in 2017 (United Nations Development Programme 2018). These indicators give some information about the overall health and quality of life of the populations of the countries of origin of the asylum seekers and refugees that arrived during the European migrant and refugee crisis in Germany between 2014 and 2017. In the current study, the mental HrQoL of asylum seekers and refugees from Afghanistan was statistically significantly lower than of asylum seekers and refugees from other countries. Consequently, it is also necessary to identify and address the health care systems' problems in the asylum seekers' and refugees' countries of origin. Among certainly many other economic and political problems, the health care systems in those countries need to be developed to be accessible and effective. Furthermore, the local problems that are susceptible of change, such as difficulties in trusting, understanding, accessing and navigating the health care system, need to be addressed (Giacco et al. 2018).

The mean PCS score of asylum seekers and refugees was within the range compared with the mean PCS scores of representative samples of the total German population (53.4 vs. 51.4 and 61.0), whereas the mean MCS score of asylum seekers and refugees was lower (47.9 vs. 49.3 and 62.0) (Ellert and Kurth 2013, Wirtz et al. 2018). However, comparability of PCS and MCS scores of the asylum seeker and refugee population in the current study and those of the representative German population samples is limited. The PCS and MCS scores of the one German population sample were calculated based on the SF-36, whereas the PCS and MCS scores in the current study were calculated based on its short version, the SF-12 (Ellert and Kurth 2013). Yet, validation studies were able to reproduce more than $90 \%$ of the variance in PCS-36 and MCS-36 scores based on PCS-12 and MCS-12 scores (Ware et al. 1996, Gandek et al. 1998). Furthermore, comparability is limited, as the general German population was older (49 vs. 33 years) and less persons were male (49\% vs. 61\%) compared with persons of the current study (Statistisches Bundesamt 2019a). In general, comparison of HrQoL of asylum seekers and refugees that arrived in Germany may not be comparable to other migrant groups or asylum seekers and refugees that arrived in other European countries.

The refugee samples of the SOEP were subject to possible restricted representativeness of the target population of incoming asylum seekers and refugees. This may be due to identification difficulties by responsible authorities during the times of highest influx in 2015, difficulties in keeping track of persons of the sample due the high residential mobility and the possibility that persons of the sample might have had insufficient language skills (Kühne et al. 2019). 
However, to overcome these potential problems, a two-stage clustered disproportional stratified design was used for sampling, and persons were added at later points who were otherwise not covered. Furthermore, all interview materials have been translated to seven languages, besides German (Kühne et al. 2019). Finally, limitations of the SOEP survey in general, relating to interview materials, the interviewers, the underrepresentation of ethnic minorities and the overrepresentation of well-educated and well-integrated persons as well as nonresponse or selection bias apply to the current study.

Persons with different nationalities might not have the same probability of answering items of HrQoL-instruments in the same way and therefore, comparison of PCS and MCS scores between different populations should be interpreted with caution (Benítez-Borrego et al. 2016, Gibbons et al. 2018). To our knowledge, the SF-12v2 has not yet been validated in the languages Pashto, Urdu and Kurjmanji. It may be possible that the SF-12v2 performed in different ways for persons with different nationalities and therefore differential item functioning may be present (Gibbons et al. 2018, Langer et al. 2008). Furthermore, it is unknown whether causes of flight and harsh conditions during the flight have an influence on the current HrQoL of asylum seekers and refugees (Jesuthasan et al. 2018). In the current study, the outcome of asylum application had a statistically significant effect on the MCS score, whereas years since arrival in the receiving country was not associated with HrQoL. This was in accordance with a study that assessed the associations of the outcome of asylum application on mental health and quality of life (Winkler et al. 2019).

The sample of this study might be representative for asylum seekers and refugees in Germany to some extent, at least with respect to the distribution of outcomes of asylum applications and the distribution of Afghan and Iraqi nationalities. The protection status of the sample of this study was distributed comparably to all asylum seekers in the German population in 2017 (Statistisches Bundesamt 2019b). The distribution of Afghan and Iraqi nationalities in the sample of the current study was similar to the distribution of nationalities in the German population (13\% and $14 \%$ vs. $12 \%$ and $11 \%$ ), however, in the sample of the current study, a greater proportion was with Syrian nationality (50\% vs. 31\%) (Statistisches Bundesamt 2019b). The persons of the sample of the current study were slightly older (33 vs. 29 years) and a comparable amount of persons was female (39\% vs. 36\%) compared with all asylum seekers in the German population at their initial entry (Statistisches Bundesamt 2019b).

\section{Strengths and Limitations}

To our knowledge, this was the first study of HrQoL of asylum seekers and refugees that arrived during the European migrant and refugee crisis in Germany between 2014 and 2017. The current study profited from cross-sectional data based on a large representative German household panel. Furthermore, this study was able to examine associations between HrQoL of asylum seekers and refugees, selected sociodemographic factors. However, some further limitations not discussed above have to be mentioned. First, as 
persons of the current sample were older and were more often with Syrian nationality, compared with all asylum seekers in the German population, generalizability might be limited to asylum seekers and refugees that arrived during the European migrant and refugee crisis in Germany. Second, the analyses of this study were based on crosssectional data and therefore no conclusions on causality can be drawn.

\section{Conclusion}

Asylum seekers and refugees that arrived during the European migrant and refugee crisis in Germany between 2014 and 2017 have a higher physical and a lower mental HrQoL than the German norm. Female sex, older age, unemployment and having never been married, separated or divorced was associated with lower HrQoL. Of the largest ethnical groups of asylum seekers and refugees, the three groups of Syrians, Afghans and Eritreans, differ inherently in their mental HrQoL. Policy makers and health care providers should focus on those factors that influence health of asylum seekers and refugees that can be influenced on the one hand and that were significantly associated with reduced $\mathrm{HrQoL}$ in the current study. One measure could be the access to the labor market, as unemployment was significantly associated with lower PCS and MCS scores. Furthermore, health care needs to give special attention to of asylum seekers and refugees with significantly reduced mental $\mathrm{HrQoL}$, such as asylum seekers and refugees from Afghanistan. Further research is needed in order to analyze HrQoL of asylum seekers and refugees in Germany longitudinally, to compare the HrQoL of refugees with the HrQoL of the German population and to analyze the effect of ethnicity on HrQoL in asylum seekers and refugees more extensively. More research is also needed on the influence of those factors that influence HrQoL of asylum seekers and refugees that become relevant after arrival Germany, such as social exclusion, cultural values and separation from loved ones.

Acknowledgements The data used in this study was made available by the German Socio-Economic Panel Study (SOEP) at the German Institute for Economic Research (DIW), Berlin.

Authors' Contributions T.G. made substantial contributions to conception and design of the study, the analysis and interpretation of data and drafted the manuscript. H.-H.K. and J.D. made substantial contributions to the analysis and interpretation of data and drafting of the manuscript. S.R.-H. made substantial contributions to conception and design, and critically revised the manuscript. All authors read and approved the final manuscript.

Funding Open Access funding enabled and organized by Projekt DEAL. This research received no specific grant from any funding agency in the public, commercial, or not-for-profit sectors.

Data Availability The data can be applied for via the website of the German Institute for Economic Research (DIW), Berlin. It is available for scientific, uncommercial use for researchers free of charge.

\section{Compliance with Ethical Standards}

Conflict of Interest The authors declare that they have no conflicts of interest.

Code Availability The code used during the current study is available from the corresponding author on reasonable request for all interested researchers. Interested parties may contact the Department of Health 
Economics and Health Services Research, University Medical Center Hamburg-Eppendorf (contact information: Dr. Thomas Grochtdreis, t.grochtdreis@uke.de, +49 (0)407410-52405).

Ethics Approval This study was a secondary analysis of anonymized data, and therefore an ethics approval was not required. Participants gave their informed consent prior to data collection. Detailed information on ethical clearance and informed consent given by the participants related to the German Socio-Economic Panel Study (SOEP) can be found on the website of the German Institute for Economic Research (DIW), Berlin (https://www.diw.de/soep).

Open Access This article is licensed under a Creative Commons Attribution 4.0 International License, which permits use, sharing, adaptation, distribution and reproduction in any medium or format, as long as you give appropriate credit to the original author(s) and the source, provide a link to the Creative Commons licence, and indicate if changes were made. The images or other third party material in this article are included in the article's Creative Commons licence, unless indicated otherwise in a credit line to the material. If material is not included in the article's Creative Commons licence and your intended use is not permitted by statutory regulation or exceeds the permitted use, you will need to obtain permission directly from the copyright holder. To view a copy of this licence, visit http://creativecommons.org/licenses/by/4.0/.

\section{References}

Adedeji, A., \& Bullinger, M. (2019). Subjective integration and quality of life of sub-Saharan African migrants in Germany. Public Health, 174, 134-144. https://doi.org/10.1016/j.puhe.2019.05.031.

Andersen, H. H., Mühlbacher, A., \& Nübling, M. (2007). Die SOEP-Version des SF 12 als Instrument gesundheitsökonomischer Analysen. Berlin: German Institute for Economic Research.

Angelini, V., Cavapozzi, D., Corazzini, L., \& Paccagnella, O. (2012). Age, health and life satisfaction among older Europeans. Social Indicators Research, 105, 293-308. https://doi.org/10.1007/s11205-011-9882-x.

Bauhoff, S., \& Gopffarth, D. (2018). Asylum-seekers in Germany differ from regularly insured in their morbidity, utilizations and costs of care. PLoS One, 13, e0197881. https://doi.org/10.1371/journal.pone. 0197881.

Benítez-Borrego, S., Mancho-Fora, N., Farràs-Permanyer, L., Urzúa-Morales, A., \& Guàrdia-Olmos, J. (2016). Differential item functioning of WHOQOL-BREF in nine Iberoamerican countries. Revista Iberoamericana de Psicología y Salud, 7, 51-59. https://doi.org/10.1016/j.rips.2016.04.001.

Biddle, L., Menold, N., Bentner, M., Nost, S., Jahn, R., Ziegler, S., et al. (2019). Health monitoring among asylum seekers and refugees: A state-wide, cross-sectional, population-based study in Germany. Emerging Themes in Epidemiology, 16, 3. https://doi.org/10.1186/s12982-019-0085-2.

Bischoff, A., Schneider, M., Denhaerynck, K., \& Battegay, E. (2009). Health and ill health of asylum seekers in Switzerland: An epidemiological study. European Journal of Public Health, 19, 59-64. https://doi.org/ 10.1093/eurpub/ckn113.

Dickhaus, T. (2014). Classes of multiple test procedures. In T. Dickhaus (Ed.), Simultaneous statistical inference: With applications in the life sciences (pp. 29-45). Berlin: Springer.

Ellert, U., \& Kurth, B. M. (2013). Health related quality of life in adults in Germany: Results of the German health interview and examination survey for adults (DEGS1). Bundesgesundheitsblatt Gesundheitsforschung - Gesundheitsschutz, 56, 643-649. https://doi.org/10.1007/s00103-013-1700-y.

Eurostat (2019) Asylum and first time asylum applicants - annual aggregated data. Eurostat. https://ec.europa. eu/eurostat/databrowser/view/tps00191/default/table?lang=en. Accessed 27 August 2019.

Gandek, B., Ware, J. E., Aaronson, N. K., Apolone, G., Bjorner, J. B., Brazier, J. E., Bullinger, M., Kaasa, S., Leplege, A., Prieto, L., \& Sullivan, M. (1998). Cross-validation of item selection and scoring for the SF12 health survey in nine countries: Results from the IQOLA project. International Quality of Life Assessment. Journal of Clinical Epidemiology, 51, 1171-1178. https://doi.org/10.1016/s0895-4356(98) 00109-7.

Giacco, D., Laxhman, N., \& Priebe, S. (2018). Prevalence of and risk factors for mental disorders in refugees. Seminars in Cell and Developmental Biology, 77, 144-152. https://doi.org/10.1016/j.semcdb.2017.11. 030 .

Gibbons, C. J., Skevington, S. M., \& WHOQOL Group. (2018). Adjusting for cross-cultural differences in computer-adaptive tests of quality of life. Quality of Life Research, 27, 1027-1039. https://doi.org/10. 1007/s11136-017-1738-7. 
Global Burden of Disease 2017 Disease and Injury Incidence and Prevalence Collaborators. (2018). Global, regional, and national incidence, prevalence, and years lived with disability for 354 diseases and injuries for 195 countries and territories, 1990-2017: A systematic analysis for the global burden of disease study 2017. Lancet, 392, 1789-1858. https://doi.org/10.1016/S0140-6736(18)32279-7.

Global Burden of Disease 2017 Mortality Collaborators. (2018). Global, regional, and national age-sexspecific mortality and life expectancy, 1950-2017: A systematic analysis for the global burden of disease study 2017. Lancet, 392, 1684-1735. https://doi.org/10.1016/S0140-6736(18)31891-9.

Global Burden of Disease DALYs and HALE Collaborators. (2018). Global, regional, and national disabilityadjusted life-years (DALYs) for 359 diseases and injuries and healthy life expectancy (HALE) for 195 countries and territories, 1990-2017: A systematic analysis for the global burden of disease study 2017. Lancet, 392, 1859-1922. https://doi.org/10.1016/S0140-6736(18)32335-3.

Goebel, J., Grabka, M. M., Liebig, S., Kroh, M., Richter, D., Schroder, C., et al. (2019). The German socioeconomic panel (SOEP). Journal of Economics and Statistics, 239, 345-360. https://doi.org/10.1515/ jbnst-2018-0022.

Goodman, L. F., Jensen, G. W., Galante, J. M., Farmer, D. L., \& Taché, S. (2018). A cross-sectional investigation of the health needs of asylum seekers in a refugee clinic in Germany. BMC Family Practice, 19, 64. https://doi.org/10.1186/s12875-018-0758-x.

Gottvall, M., Sjölund, S., Arwidson, C., \& Saboonchi, F. (2019). Health-related quality of life among Syrian refugees resettled in Sweden. Quality of Life Research, 29, 505-514. https://doi.org/10.1007/s11136-01902323-5.

Grochtdreis, T., Dams, J., König, H.-H., \& Konnopka, A. (2019). Health-related quality of life measured with the EQ-5D-5L: Estimation of normative index values based on a representative German population sample and value set. European Journal of Health Economics, 20, 933-944. https://doi.org/10.1007/ s10198-019-01054-1.

Igel, U., Brähler, E., \& Grande, G. (2010). The influence of perceived discrimination on health in migrants. Psychiatrische Praxis, 37, 183-190. https://doi.org/10.1055/s-0029-1223508.

International Organization for Migration (2020) Migration and health. International Organization for Migration. https://migrationdataportal.org/themes/migration-and-health. Accessed 08 June 2020.

Jesuthasan, J., Sönmez, E., Abels, I., Kurmeyer, C., Gutermann, J., Kimbel, R., et al. (2018). Near-death experiences, attacks by family members, and absence of health care in their home countries affect the quality of life of refugee women in Germany: A multi-region, cross-sectional, gender-sensitive study. BMC Medicine, 16, 15. https://doi.org/10.1186/s12916-017-1003-5.

Kroh, M., Kühne, S., Jacobsen, J., Siegert, M., \& Siegers, R. (2017). Sampling, nonresponse, and integrated weighting of the 2016 IAB-BAMF-SOEP survey of refugees (M3/M4) - Revised version. Berlin: German Institute for Economic Research.

Kühne, S., Jacobsen, J., \& Kroh, M. (2019). Sampling in times of high immigration: The survey process of the IAB-BAMF-SOEP survey of refugees. Survey Methods: Insights from the Field. https://doi.org/10.13094/ SMIF-2019-00005.

Langer, M. M., Hill, C. D., Thissen, D., Burwinkle, T. M., Varni, J. W., \& DeWalt, D. A. (2008). Item response theory detected differential item functioning between healthy and ill children in quality-of-life measures. Journal of Clinical Epidemiology, 61, 268-276. https://doi.org/10.1016/j.jclinepi.2007.05.002.

Laukamp, A., Prüfer-Krämer, L., Fischer, F., \& Krämer, A. (2019). Health of Syrian unaccompanied asylum seeking adolescents (UASA) at first medical examination in Germany in comparison to UASA from other world regions. BMC International Health and Human Rights, 19, 5. https://doi.org/10.1186/s12914-0190192-8.

Leiler, A., Bjärtå, A., Ekdahl, J., \& Wasteson, E. (2019). Mental health and quality of life among asylum seekers and refugees living in refugee housing facilities in Sweden. Social Psychiatry and Psychiatric Epidemiology, 54, 543-551. https://doi.org/10.1007/s00127-018-1651-6.

Liebau, E. (2016). Mental health and quality of life of immigrants and their descendants in the SOEP in the years 1984-2016. Psychotherapie Psychosomatik Medizinische Psychologie, 66, 393-396. https://doi.org/ 10.1055/s-0042-116439.

Marquardt, L., Krämer, A., Fischer, F., \& Prüfer-Krämer, L. (2016). Health status and disease burden of unaccompanied asylum-seeking adolescents in Bielefeld, Germany: Cross-sectional pilot study. Tropical Medicine and International Health, 21, 210-218. https://doi.org/10.1111/tmi.12649.

Nante, N., Gialluca, L., De Corso, M., Troiano, G., Verzuri, A., \& Messina, G. (2016). Quality of life in refugees and asylum seekers in Italy: A pilot study. Annali dell'Istituto Superiore di Sanità, 52, 424-427. https://doi.org/10.4415/ann_16_03_14. 
Nesterko, Y., Braehler, E., Grande, G., \& Glaesmer, H. (2013). Life satisfaction and health-related quality of life in immigrants and native-born Germans: The role of immigration-related factors. Quality of Life Research, 22, 1005-1013. https://doi.org/10.1007/s11136-012-0239-y.

Nesterko, Y., Jackle, D., Friedrich, M., Holzapfel, L., \& Glaesmer, H. (2019). Prevalence of post-traumatic stress disorder, depression and somatisation in recently arrived refugees in Germany: An epidemiological study. Epidemiology and Psychiatric Sciences, 29, e40. https://doi.org/10.1017/S2045796019000325.

Nesterko, Y., Jackle, D., Friedrich, M., Holzapfel, L., \& Glaesmer, H. (2020a). Factors predicting symptoms of somatization, depression, anxiety, post-traumatic stress disorder, self-rated mental and physical health among recently arrived refugees in Germany. Conflict and Health, 14, 44. https://doi.org/10.1186/ s13031-020-00291-Z.

Nesterko, Y., Jackle, D., Friedrich, M., Holzapfel, L., \& Glaesmer, H. (2020b). Health care needs among recently arrived refugees in Germany: A cross-sectional, epidemiological study. International Journal of Public Health, 65, 811-821. https://doi.org/10.1007/s00038-020-01408-0.

Nielsen, S. S., \& Krasnik, A. (2010). Poorer self-perceived health among migrants and ethnic minorities versus the majority population in Europe: A systematic review. International Journal of Public Health, 55, 357-371. https://doi.org/10.1007/s00038-010-0145-4.

Nübling, M., Andersen, H. H., \& Mühlbacher, A. (2006). Entwicklung eines Verfahrens zur Berechnung der Körperlichen und psychischen Summenskalen auf Basis der SOEP-Version des SF 12 (Algorithmus). Berlin: German Institute for Economic Research.

Razum, O., \& Rohrmann, S. (2002). The healthy migrant effect: Role of selection and late entry bias. Gesundheitswesen, 64, 82-88. https://doi.org/10.1055/s-2002-20271.

Richter, K., Peter, L., Lehfeld, H., Zäske, H., Brar-Reissinger, S., \& Niklewski, G. (2018). Prevalence of psychiatric diagnoses in asylum seekers with follow-up. BMC Psychiatry, 18, 206. https://doi.org/10. 1186/s12888-018-1783-y.

Schmidt, S., Muhlan, H., \& Power, M. (2006). The EUROHIS-QOL 8-item index: Psychometric results of a cross-cultural field study. European Journal of Public Health, 16, 420-428. https://doi.org/10.1093/ eurpub/cki155.

Schupp, J., Wagner, G., Nübling, M., Andersen, H. H., \& Mühlbacher, A. (2007). Computation of standard values for physical and mental health scale scores using the SOEP version of SF12v2. Schmollers Jahrbuch: Journal of Applied Social Science Studies / Zeitschrift für Wirtschafts- und Sozialwissenschaften, 127, 171-182.

Statistisches Bundesamt. (2019a). Statistisches Jahrbuch. Deutschland und Internationales. Wiesbaden: Statistisches Bundesamt.

Statistisches Bundesamt (2019b) Bevölkerung und Erwerbstätigkeit. Schutzsuchende Ergebnisse des Ausländerzentralregisters 2018. Wiesbaden: Statistisches Bundesamt.

Theuring, S., Friedrich-Janicke, B., Portner, K., Trebesch, I., Durst, A., Dieckmann, S., et al. (2016). Screening for infectious diseases among unaccompanied minor refugees in Berlin, 2014-2015. European Journal of Epidemiology, 31, 707-710. https://doi.org/10.1007/s10654-016-0187-x.

UNHCR (2016) Global trends. Forced displacement in 2015. UNHCR. https://www.unhcr.org/576408cd7. pdf. Accessed 26 August 2019.

UNHCR (2020) Asylum and migration. UNHCR. https://www.unhcr.org/asylum-and-migration.html. Accessed 26 May 2020.

United Nations Development Programme (2018) Human Development Indices and Indicators. 2018 Statistical Update. United Nations Development Programme. http://hdr.undp.org/sites/default/files/2018_human_ development_statistical_update.pdf. Accessed 13 January 2020.

van Berlaer, G., Bohle Carbonell, F., Manantsoa, S., de Bethune, X., Buyl, R., Debacker, M., et al. (2016). A refugee camp in the Centre of Europe: Clinical characteristics of asylum seekers arriving in Brussels. BMJ Open, 6, e013963. https://doi.org/10.1136/bmjopen-2016-013963.

Ware, J. J., Kosinski, M., \& Keller, S. D. (1996). A 12-item short-form health survey: Construction of scales and preliminary tests of reliability and validity. Medical Care, 34, 220-233. https://doi.org/10.1097/ 00005650-199603000-00003.

Wetzke, M., Happle, C., Vakilzadeh, A., Ernst, D., Sogkas, G., Schmidt, R. E., et al. (2018). Healthcare utilization in a large cohort of asylum seekers entering Western Europe in 2015. International Journal of Environmental Research and Public Health, 15, 2163. https://doi.org/10.3390/ijerph15102163.

Winkler, J. G., Brandl, E. J., Bretz, H. J., Heinz, A., \& Schouler-Ocak, M. (2019). The influence of residence status on psychiatric symptom load of asylum seekers in Germany. Psychiatrische Praxis, 46, 191-199. https://doi.org/10.1055/a-0806-3568. 
Wirtz, M. A., Morfeld, M., Glaesmer, H., \& Brähler, E. (2018). Standardization of the SF-12 version 2.0 assessing health-related quality of life in a representative German sample. Diagnostica, 64, 215-226. https://doi.org/10.1026/0012-1924/a000205.

Publisher's Note Springer Nature remains neutral with regard to jurisdictional claims in published maps and institutional affiliations. 